\title{
حالات بعض الأنواع البكتيرية الأكثر شيوعًا في مرضى التليف الكيسي في جدة، المملكة العربية السعودية
}

\author{
أحمد محمود الهجن 'و" ، خليجة محمد بن محفوظ'

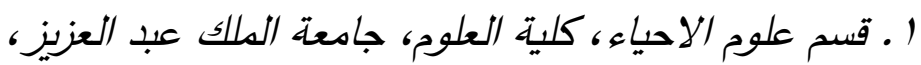

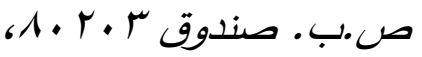

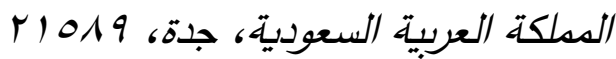

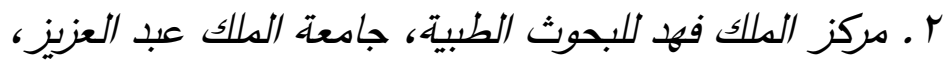

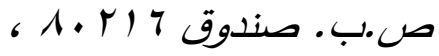$$
\text { المملكة العربية السعودية، جلة هوف ، }
$$

مستخلص. يُعد الفقدان التدريجي لوظائف الرئة بسبب الاستجابة الالتهابية للاستعمار البكتيري السبب الرئيسي لوفيات

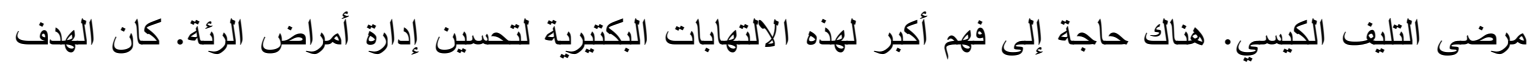

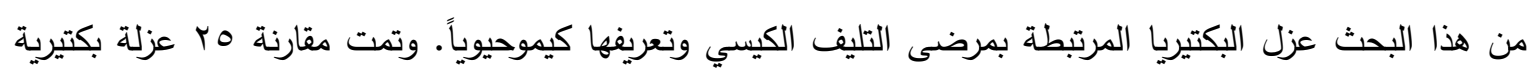
من مرضى التليف الكيسي مع ؟r عزلة من مرضى غير التليف الكيسي. تم عزل أربعة أنواع مختلفة في هذه ونهي الدراسة. A. baumannii ،K. pneumoniae ،S. aureus ،P. aeruginosa . في الختام، أظهرت هذه النتائج أن مرضى التليف الكيسي في جدة لديهم أنواع بكتيرية Bacterial Species غير شائعة لدى مرضى التليف 
neonatal screening, Eur. J. Hum. Genet., vol. 10:583-590.

14. Horner, C., K.Carney and B. Bohannan, 2004. An ecological perspective on bacterial biodiversity, Proc. Roy. Soc. London Ser. BBiol. Sci., vol. 271:113-122.

15. Lambiase, A., V. Raia, M. Del Pezzo, A.Sepe, V.Carnovale and F. Rossano, 2006. Microbiology of airway disease in a cohort of patients with cystic fibrosis, BMC. Infect. Dis., vol. 6:4.

16. Rahal, J. and C. Urban, 2000.Acinetobacter. Semin.Respir. Crit. Care. Med. Vol. 21:341-348.

17. Leão, R., R. Pereira, T. Folescu, R.Albano, E.Santos, L.Junior and E. Marques, 2011. KPC-2 Carbapenemase-producing Klebsiella pneumoniae isolates from patients with Cystic Fibrosis, J.Cyst.Fib. vol.10:140-141.

18. Bittar, F., H. Richet, J.Dubus, N. Stremler, J.Sarles and D.Raoult, 2008. Molecular detection of multiple emerging pathogens in sputa from cystic fibrosis patients, PLoS. One. vol.3:65.

19. Khanbabaee, G., M. Akbarizadeh , M.Sayyari, M. Ashayeri-Panah , F. Abdollahgorji, K. Sheibani and N. Rezaeig, 2012.A survey on pulmonary pathogens and their antibiotic susceptibility among cystic fibrosis patients, Braz. J. Infect. Dis., vol.16: 65-69.

20. Doering, G., S.Conway, H. Heijerma, M. Hodson, M. Hùiby, A. Smyth and D.Touw, 2000. Antibiotic therapy against Pseudomonas aeruginosa in cystic fibrosis: a European consensus, Eur. Respir. J., vol.16:749-767.

21. Nazik, H., B.Ongen, Z.Erturan and M. Salcioglu, 2007.Genotype and Antibiotic Susceptibility Patterns of Pseudomonas aeruginosa and Stenotrophomonas maltophilia Isolated from Cystic Fibrosis patients, Jpn.J.Infect.Dis. vol.60:82-86.
22. Onanuga, A. and J. Onalapo, 2008.Antimicrobial susceptibility of community-associated Staphylococcus aureus isolates from healthy women in Zaria, Trop. J. Pharm. Res., vol.7: 929-939. 711.

23. Hoerlle, J. and A. Brandelli, 2009. Antimicrobial resistance of Staphylococcus aureus isolated from the intensive care unit of a general hospital in southern Brazil, J. Infect. Dev. Ctries., vol.3:504-510.

24. Jain, R. and L. Danziger, 2004. Multidrugresistant Acinetobacter infections: an emerging challenge to clinicians, Ann. Pharmacother., vol.38:1449-1459. 
nosocomial infections [23]. A. baumannii isolates have a propensity to readily develop resistance to second and third generation antibiotics such as cefotaxime, ciprofloxacin, and giving rise to therapeutic problems [24] As next-generation antibiotics are being developed to overcome problem of resistance against available antibiotics, $A$. baumannii are developing mechanisms to resist newer antimicrobials. In this study, A. baumannii isolates showed resistance to both old and new generation antibiotics.

\section{CONCLUSIONS}

In Conclusion, in this investigation, our results show that CF patients in Jeddah had uncommon species i.e. A. baumannii and $K$. pneumoniae.

\section{Conflict of interest}

The authors declare no conflicts of interest.

\section{ACKNOWLEDGMENT}

The authors also, acknowledge assistance from the Dept. of Biological Sciences, Faculty of Science, King Abdulaziz University (KAU), Jeddah, KSA.

\section{REFERENCES}

1. Yankas, J., 2004. Cystic fibrosis adult care consensus conference report, Chest, 125: 139.

2. Cystic Fibrosis Mutation Database, 2007. http://www.genet.sickkids.on.ca/cftr/app

3. Flume, A., P. Mogayzel, K. Robinson, C. Goss, R. Rosenblatt, R. Kuhn and B. Marshall, 2009. Cystic Fibrosis Pulmonary Guidelines (Treatment of Pulmonary Exacerbations). Am. J. Respir. Crit. Care Med., 180: 802-808.

4. Rosenfeld, M., F.Ratjen, L. Brumback, S.Daniel, R. Rowbotham, S.McNamara, R.Johnson, R.Kronmal and S.Davis, 2012. Inhaled Hypertonic Saline in Infants and Children Younger Than 6 Years with Cystic Fibrosis, J.A.M.A., vol. 307:2269-2277.
5. Ratjen, F. and G. Doring, 2003.Cystic fibrosis, Lancet, vol. 361:681-689.

6. Nazer, H., E.Riff, N. Sakati, R. Mathew, M. A. Majeed-Saidan and H. Harfi, 1989. Cystic fibrosis in Saudi Arabia, Eur. J. Pediatr., vol.148:330-332.

7. Kambouris,M., H. Banjar, I.Mogarri, H.Nazer, M.Al-Hamed and B. Meyer,2000.Identification of Novel Cystic Fibrosis Mutations in Arabs with CF: Their impact on the CFTR mutation detection rate in Arab population, Euro J Pediac, vol.159:303-309.

8. Chaparro, C., J.Maurer, C.Gutierrez, M. Krajden, C.Chan, T. Winton, S. Keshavjee, M.Scavuzzo, E. Tullis, M. Hutcheon and S. Kesten,2001. Infection with Burkholderia cepacia in cystic fibrosis: Outcome following lung transplantation, Am.J.Respir.Crit.Care.Med, vol.163:43-48.

9. Döring, G., S.Jansen, H. Noll, H.Grupp, F. Frank, K.Botzenhart, K.Magdorf and U. Wahn, 1996. Distribution and transmission of Pseudomonas aeruginosa and Burkholderia cepacia in a hospital ward, Pediatr. Pulmonol. vol.21:90-100.

10. Davis, P., M. Drumm and M.Konstan, 1996. Cystic fibrosis, Am. J. Respir. Crit. Care Med., vol.154:1229- 1256.

11. Gibson, R., L.Burns and B. Ramsey, 2003. Pathophysiology and management of respiratory infections in cystic fibrosis, Am. J. Respir. Crit. Care Med., vol.168:918951.

12. Lyczak, J., C. Cannon and G.Pier, 2003.Lung infections associated with cystic fibrosis, Clin. Microbiol. Rev., vol. 15:194222.

13. McCormick, J., M.W. Green, G. Mehta, F.Culross and A.Mehta, 2002.Demographics of the UK cystic fibrosis population: implications for 


\section{DISCUSSION}

$\mathrm{CF}$ is the most common lethal inherited disease in white persons [10]. Chronic airway inflammation and infection are the greatest causes of morbidity and mortality in $\mathrm{CF}$ patients [11]. Lungs of CF patients are often colonized or infected in infancy and early childhood with organisms, such as Staphylococcus aureus and Haemophilus influenza, that may damage the epithelial surfaces, leading to increased attachment of, and eventual replacement by $P$. aeruginosa [12]. Approximately 30,000 Americans have $\mathrm{CF}$, and there are an estimated 1,000 new cases diagnosed each year (Cystic Fibrosis Foundation) and there are more than 5,000 registered $\mathrm{CF}$ patients in the UK [13]. The incidence of CF in Saudi Arabia was reported to be 1 in 4243 children [6]. The Microbiological analysis of clinical specimens has relied traditionally on cultivation prior to identification, have gained widespread acceptance for the study of bacterial communities in samples [14]. The data obtained in this study found that $P$. aeruginosa is present in 56\% (14 of 25) of CF samples and $37.5 \%$ (9 of 24) in non CF samples, being the highest rate of colonization in agreement with Cystic Fibrosis Foundation Report, USA, in 2006 and Cystic Fibrosis Foundation Report, UK, in 2010. S. aureus was isolated from $16 \%$ of CF samples and $16.64 \%$ of non CF samples. As reported in previous studies on the prevalence and antimicrobial susceptibility of bacterial isolates from CF patients in USA, Germany, and South America, we found that $S$. aureus and $P$. aeruginosa are the most frequent pathogens in this population [15]. In 2010 , the prevalence of $S$. aureus was highest (70.7\%) among children and in older age the prevalence of $S$. aureus isolates declined as the prevalence of $P$. aeruginosa increased. $A$. baumannii is an unusual organism in $\mathrm{CF}$ patients [16]. In this study A. baumannii was presented in $16 \%$ of CF samples (4 of 25) and $37.5 \%$ in non-CF samples (9 of 24). In comparing this result with study in the USA in 2010, A. baumannii was found in 5 patients out of 53 U.S patients, which indicated the infrequency of this species in these patients. There is a paucity of reports regarding colonization of $K$. pneumoniae in $\mathrm{CF}$ patients $[17,18]$. Its present in $12 \%$ of CF samples (3 patients) and $8.32 \%$ in non-CF samples (2 patients), it was the lowest prevalent microorganism isolated from our patients. In contrasts with this result, $K$. pneumoniae was the second most pathogen isolated from $\mathrm{CF}$ patients in Brazil [19]. Antibiotic therapy reduces the morbidity of CF lung disease. Although the treatment of lung infection in $\mathrm{CF}$ patients is based on the patient's age, the colonizing organisms, and the severity of the patient's pulmonary exacerbation, choosing antibiotic according to the resistance pattern of the strains is highly recommended [20]. The following antibiotic susceptibility results were observed in this study; $P$. aeruginosa isolates recorded a high resistance for Ampicillin 95\% and Augmentin 95.6 then Ceftriaxone 69.44\%, Aztreonam, 60\%, and Cefotaxime 52\%. The $P$. aeruginosa isolates were most susceptible to Meropenem 78\%, Imipenem 78\%, and Ceftazidime $60 \%$. The susceptibility to Meropenem and Imipenem was higher in another study, Meropenem $82 \%$, and Imipenem $84 \%$ [21]. The differences of susceptibility patterns between this and other studies may be related to variations in the isolated strain and the use of infection control practices. The $S$. aureus isolates showed 100\% sensitivity to vancomycin, teicoplanin, and cefoxitin (a measure of methicillin resistance). The susceptibility test results showed ampicillin and Augmentin to be the least effective agents with $75 \%$ bacterial resistance, this has been widely reported for $S$. aureus from various sites of healthy subjects [22] and 


\begin{tabular}{|c|c|c|c|c|c|c|c|c|c|c|c|c|c|c|c|c|c|c|c|c|c|c|c|c|}
\hline CRO & 8 & 4 & 2 & 8 & 1 & 0 & 4 & 0 & 0 & 8 & 1 & 0 & 2 & 1 & 0 & 0 & 2 & 0 & 0 & 0 & 0 & 0 & 0 & 0 \\
\hline TZP & 2 & 9 & 3 & 7 & 2 & 0 & 4 & 0 & 0 & 8 & 1 & 0 & 2 & 1 & 0 & 1 & 1 & 0 & 0 & 0 & 0 & 0 & 0 & 0 \\
\hline CTX & 5 & 7 & 2 & 7 & 1 & 1 & 4 & 0 & 0 & 8 & 0 & 1 & 2 & 0 & 1 & 0 & 1 & 1 & 0 & 0 & 0 & 0 & 0 & 0 \\
\hline FEB & 3 & 10 & 1 & 7 & 1 & 1 & 4 & 0 & 0 & 8 & 1 & 0 & 2 & 1 & 0 & 0 & 2 & 0 & 0 & 0 & 0 & 0 & 0 & 0 \\
\hline MEM & 1 & 12 & 1 & 3 & 6 & 0 & 4 & 0 & 0 & 8 & 1 & 0 & 0 & 3 & 0 & 0 & 2 & 0 & 0 & 0 & 0 & 0 & 0 & 0 \\
\hline KF & 0 & 0 & 0 & 0 & 0 & 0 & 0 & 0 & 0 & 0 & 0 & 0 & 0 & 0 & 0 & 0 & 0 & 0 & 2 & 2 & 0 & 1 & 2 & 1 \\
\hline TS & 0 & 0 & 0 & 0 & 0 & 0 & 0 & 0 & 0 & 0 & 0 & 0 & 0 & 0 & 0 & 0 & 0 & 0 & 1 & 3 & 0 & 0 & 4 & 0 \\
\hline PG & 0 & 0 & 0 & 0 & 0 & 0 & 0 & 0 & 0 & 0 & 0 & 0 & 0 & 0 & 0 & 0 & 0 & 0 & 0 & 4 & 0 & 2 & 2 & 0 \\
\hline E & 0 & 0 & 0 & 0 & 0 & 0 & 0 & 0 & 0 & 0 & 0 & 0 & 0 & 0 & 0 & 0 & 0 & 0 & 3 & 1 & 0 & 3 & 1 & 0 \\
\hline CD & 0 & 0 & 0 & 0 & 0 & 0 & 0 & 0 & 0 & 0 & 0 & 0 & 0 & 0 & 0 & 0 & 0 & 0 & 2 & 1 & 1 & 2 & 2 & 0 \\
\hline TEC & 0 & 0 & 0 & 0 & 0 & 0 & 0 & 0 & 0 & 0 & 0 & 0 & 0 & 0 & 0 & 0 & 0 & 0 & 0 & 4 & 0 & 0 & 4 & 0 \\
\hline OX & 0 & 0 & 0 & 0 & 0 & 0 & 0 & 0 & 0 & 0 & 0 & 0 & 0 & 0 & 0 & 0 & 0 & 0 & 1 & 3 & 0 & 0 & 4 & 0 \\
\hline VA & 0 & 0 & 0 & 0 & 0 & 0 & 0 & 0 & 0 & 0 & 0 & 0 & 0 & 0 & 0 & 0 & 0 & 0 & 0 & 4 & 0 & 0 & 4 & 0 \\
\hline
\end{tabular}

AP: Ampicillin AUG: Augmentin GM: FEB: Cefebime. MEM: Meropenem. AUG: Gentamicin FOX: Cefoxitin KF: Cephalothin TS: Cotrimoxazole AK: Amikacin CAZ: FOX: Cefoxitin KF: Cephalothin PG: Augmentin AP: Ampicillin GM: Gentamicin Ceftazidime ATM: Aztreonam. PRL: Penicillin E: Erythromycin CD: Clindamycin Piperacillin. IMI: Imipenem. CIP: OX: Oxacillin TEC: Teicoplanin V: Ciprofloxacin. CRO: Ceftriaxone. TZP: Vancomycin $\mathrm{S}=$ Sensitive $\mathrm{I}=$ Intermediate Piperacillin +Tazobactam. CTX: Cefotaxime. $\quad \mathrm{R}=$ Resistant

Table 3: MIC of bacterial isolates and its Sensitivity in CF.

\begin{tabular}{|c|c|c|c|c|c|c|c|c|c|c|c|c|}
\hline & \multicolumn{3}{|c|}{ P. aeruginosa } & \multicolumn{3}{|c|}{ A. baumannii } & \multicolumn{3}{|c|}{ K. pneumoniae } & \multicolumn{3}{|c|}{ S. aureus } \\
\hline & $\mathrm{R}$ & $\mathrm{S}$ & I & $\mathrm{R}$ & $\mathrm{S}$ & I & $\mathrm{R}$ & $\mathrm{S}$ & I & $\mathrm{R}$ & $\mathrm{S}$ & $\mathrm{I}$ \\
\hline $\mathrm{AK}$ & 39.06 & 43.4 & 17.36 & 76.92 & 23.07 & 0 & 20 & 80 & 0 & & & \\
\hline IMI & 4.34 & 95.6 & 0 & 76.92 & 23.07 & 0 & 0 & 100 & 0 & & & \\
\hline MEM & 4.34 & 95.6 & 0 & 76.92 & 15.4 & 7.7 & 0 & 100 & 0 & & & \\
\hline CTX & 43.4 & 34.7 & 8.68 & 76.92 & 23.07 & 0 & 0 & 60 & 40 & & & \\
\hline CAZ & 39.06 & 30.38 & 0 & 76.92 & 23.07 & 0 & 0 & 100 & 0 & & & \\
\hline FEB & 21.7 & 65.1 & 13.02 & 76.92 & 23.07 & 0 & 20 & 80 & 0 & & & \\
\hline $\mathrm{TZP}$ & 52.08 & 30.38 & 17.36 & 76.92 & 23.07 & 0 & 20 & 80 & 0 & & & \\
\hline GM & 0 & 100 & 0 & 100 & 0 & 0 & 0 & 100 & 0 & & & \\
\hline TEC & & & & & & & & & & 0 & 100 & 0 \\
\hline AUG & & & & & & & & & & 37.5 & 62.5 & 0 \\
\hline $\mathrm{OX}$ & & & & & & & & & & 0 & 100 & 0 \\
\hline $\mathrm{CD}$ & & & & & & & & & & 12.5 & 75 & 12.5 \\
\hline PG & & & & & & & & & & 0 & 100 & 0 \\
\hline FOX & & & & & & & & & & 0 & 100 & 0 \\
\hline GM & & & & & & & & & & 12.5 & 87.5 & 0 \\
\hline
\end{tabular}

FOX: Cefoxitin PG: Penicillin CD: Clindamycin OX: Oxacillin GM: Gentamicin AK: Amikacin CAZ: Ceftazidime IMI: Imipenem. TZP: Piperacillin +Tazobactam. CTX: Cefotaxime. EB: Cefebime. MEM: Meropenem. S= Sensitive $I=$ Intermediate $R=$ Resistance 


\begin{tabular}{|l|l|l|c|c|}
\hline P17 & M & Sputum & P. aeruginosa & A. baumannii \\
\hline P18 & M & Sputum & P. aeruginosa & K. pneumoniae \\
\hline P19 & M & Sputum & K. pneumoniae & A. baumannii \\
\hline P20 & M & Sputum & A. baumannii & P. aeruginosa \\
\hline
\end{tabular}

$\mathrm{P}=$ Patient $\quad \mathrm{G}=$ Gender $\quad \mathrm{M}=$ Male $\quad \mathrm{F}=$ Female * Patient has 2 isolates.

$P$. aeruginosa=Pseudomonas aeruginosa $S$. aureus=Staph aureus $K$. pneumoniae $=$ Klebsiella pneumoniae $\quad$ A. baumannii $=$ Acinetobacter baumannii
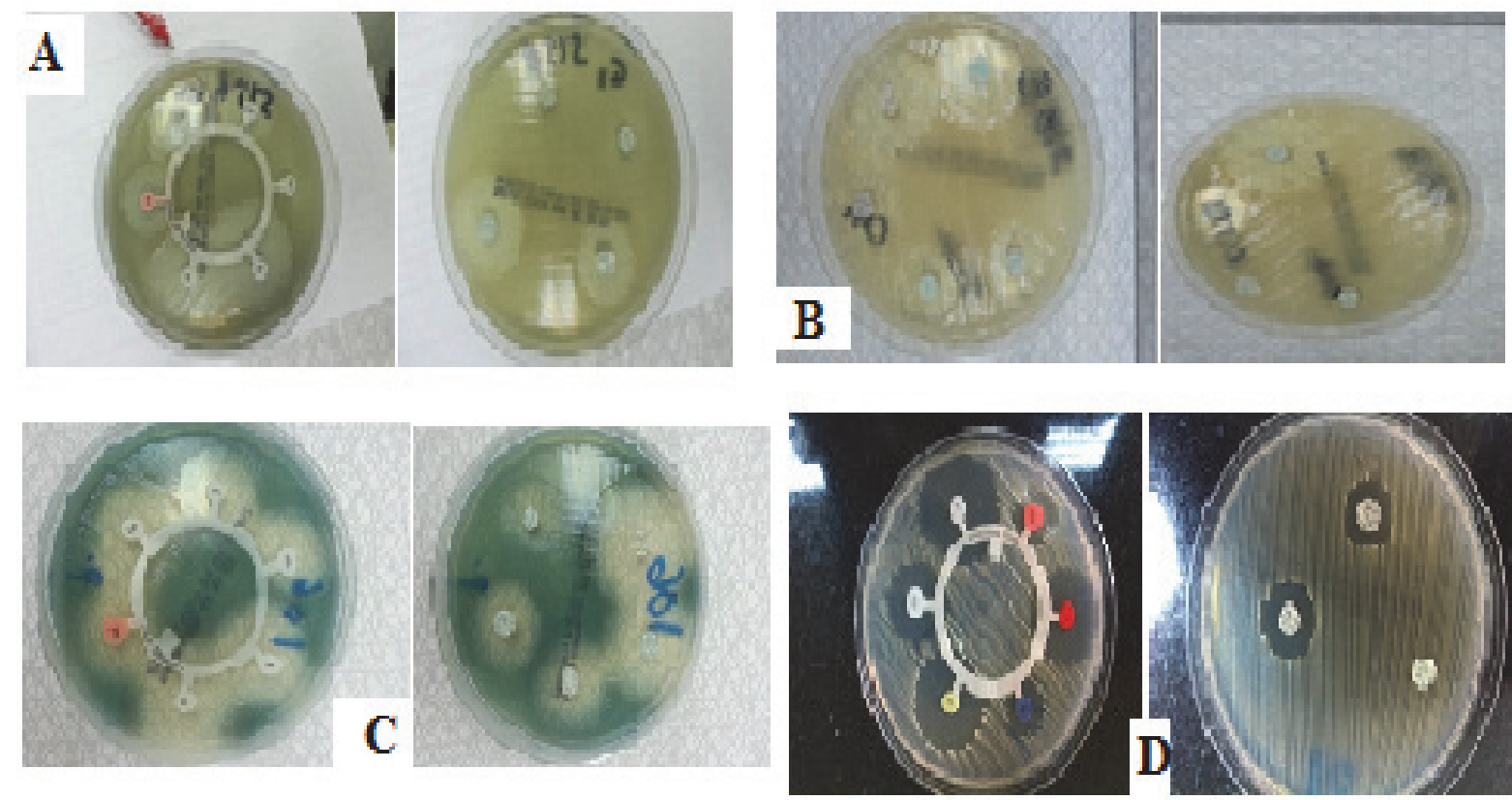

\section{Figure 1 Disk Diffusion Assay test}

Table 2. Antibiotic Sensitivity in CF and Non-CF Isolates

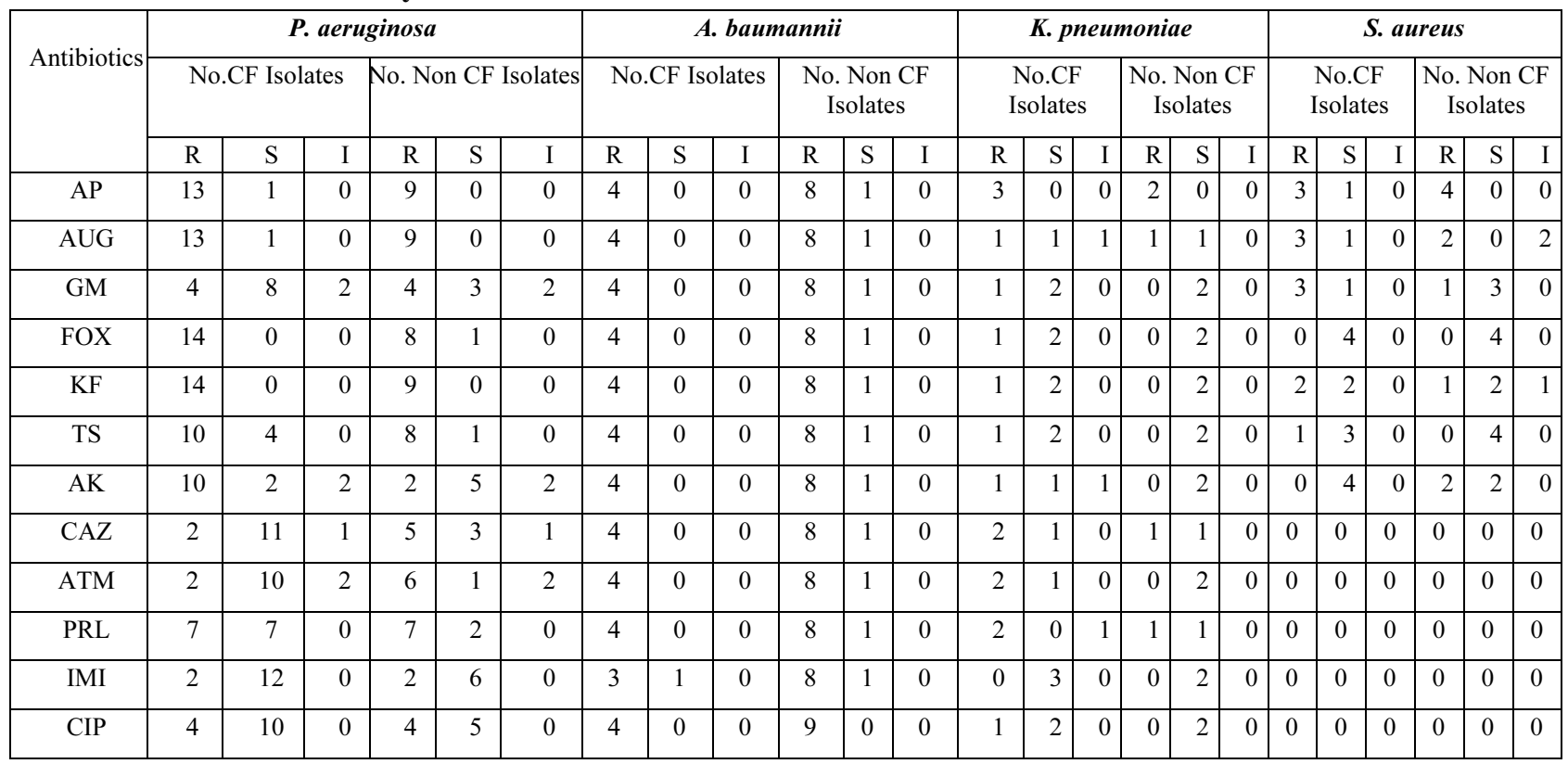


antibiotic resistance. Some samples of Pseudomonas aeruginosa could strongly resist some antibiotics such as KF, FOX, AP, AUG, $\mathrm{TS}$, AK followed by other isolated strains from CF samples, Table (2) and Fig. (1). In the case of Acinetobacter baumannii samples, most isolates were resistant to all used antibiotic except one sample was sensitive to IMI as indicated in Table (2) and Fig. (1). The antibiotic resistance patterns of Klebsiella pneumonia also indicated that most of the strains are resistant to most of the used antibiotics. Strains also are intermediate resistant as indicated in Table (2). $S$. aureus Gram- positive samples were found to resist most of the used antibiotics except FOX, PG, $\mathrm{TE}$ and VA; some samples were sensitive to commonly used antibiotics as indicated in Table (2). Results also indicated that the bacterial isolates from non- CF patients are more sensitive than strains obtained from $\mathrm{CF}$ patients for most of the used antibiotics.

MICs method (Revise highlighted text, Where's MIC values in the text or table 3)

The use of instrumentation for (MIC) can standardize the reading of end points and often produce susceptibility test results in a shorter period than manual readings because sensitive optical detection systems allow detection of subtle changes in bacterial growth. The Micro Scan Walk Away (Siemens Healthcare Diagnostics) is a large self-contained incubator/reader device that can incubate and analyze 40-96 microdilution trays and it was used in this study. The Gram-positive isolates were tested for susceptibility against seven different antibiotics and data is shown in Table (3). All Gram-negative isolates were exposed to different antibiotic and data is shown in Table (3). Results indicated that $S$. aureus samples resisted GM with $87 \%$ then $\mathrm{CD}$ and $62 \%$ but it was sensitive to PG and TEC $100 \%$. P. aeruginosa was sensitive to $\mathrm{Gm}$ with $100 \%$ and sensitive to IMI and MEM with $95 \%$, but it was resistant to TZP with $52 \%$ and CTX with $43 \%$. A. baumannii was the most resistant strain for all used antibiotics with $76 \%$ and it was resistant to GM with $100 \%$. K. pneumoniae was sensitive to GM, CAZ, IMI, and MEM with $100 \%$ then AK, FEB and TZP with $80 \%$ (Table 3, Where's the MIC value).

Make tables with font size 12 .

Table 1 Bacterial Species in Cystic Fibrosis and Non-Cystic Fibrosis Patients

\begin{tabular}{|c|c|c|c|c|}
\hline \multirow[t]{2}{*}{ NO. } & \multirow[t]{2}{*}{ Gender } & \multirow[t]{2}{*}{ Specimen } & Cystic Fibrosis & Non-Cystic Fibrosis \\
\hline & & & Bacterial species & Bacterial species \\
\hline P1 & $\mathrm{F}$ & Sputum & P. aeruginosa & $P$. aeruginosa \\
\hline P2 & $\mathrm{F}$ & Sputum & S. aureus & S. aureus \\
\hline P3 & $\mathrm{F}$ & Sputum & P. aeruginosa & P. aeruginosa \\
\hline P3* & $\mathrm{F}$ & Sputum & S. aureus & P. aeruginosa \\
\hline P4 & $\mathrm{F}$ & Sputum & P. aeruginosa & P. aeruginosa \\
\hline P5 & $\mathrm{F}$ & Sputum & P. aeruginosa & P. aeruginosa \\
\hline P5* & $\mathrm{F}$ & Sputum & K. pneumoniae & P. aeruginosa \\
\hline P6 & $\mathrm{M}$ & Sputum & P. aeruginosa & A. baumannii \\
\hline $\mathrm{P} 7$ & $\mathrm{M}$ & Sputum & P. aeruginosa & P. aeruginosa \\
\hline P7* & $\mathrm{M}$ & Sputum & A. baumannii & A. baumannii \\
\hline P8 & $\mathrm{M}$ & Sputum & P. aeruginosa & P. aeruginosa \\
\hline P9 & $\mathrm{M}$ & Sputum & P. aeruginosa & S. aureus \\
\hline P10 & $\mathrm{M}$ & sputum & S. aureus & A.baumannii \\
\hline $\mathrm{P} 11$ & $\mathrm{M}$ & Sputum & P. aeruginosa & P. aeruginosa \\
\hline P11* & $\mathrm{M}$ & Sputum & K. pneumoniae & K. pneumoniae \\
\hline $\mathrm{P} 12$ & $\mathrm{M}$ & Sputum & A. baumannii & A. baumannii \\
\hline P12* & $\mathrm{M}$ & Sputum & P. aeruginosa & S. aureus \\
\hline $\mathrm{P} 13$ & $\mathrm{M}$ & Sputum & S. aureus & S. aureus \\
\hline P14 & $\mathrm{M}$ & Sputum & P. aeruginosa & A. baumannii \\
\hline P15 & $\mathrm{M}$ & Sputum & A. baumannii & A. baumannii \\
\hline P16 & $\mathrm{M}$ & Sputum & P. aeruginosa & A. baumannii \\
\hline
\end{tabular}


Center and King Abdul Aziz Hospital \& Oncology Center from October 2011 until October 2012.

\section{Culturing of patient samples:}

All samples were cultured on the blood sheep agar, MacConkey agar, and Chocolate agar. Muller Hinton agar (Merck, Darmstadt, Germany) was used as a medium for the disk diffusion method.

\section{Bacterial identification:}

Gram staining was used to identify the pathogens in specimens and cultures. Biochemical reactions as catalase test goxidase test, API-20E test kit (Put company and catalog, and coagulase test by using rabbit plasma was performed.

\section{Antibiotic susceptibility tests}

The disk diffusion method was used as susceptibility pattern test. The test medium was Muller-Hinton agar (Merck, Darmstadt, Germany). For each isolate, one disk of each antibiotic was placed on a suitable distance on the surface of Mueller-Hinton agar plates inoculated with a bacterial suspension equivalent to $0.5 \mathrm{McFarland}$ Standard and incubated for $24 \mathrm{~h}$ at $37^{\circ} \mathrm{C}$. Disk testing was performed as recommended by CLSI (Clinical and Laboratory Standards Institute, 2005). The Antibiotics used were Amikacin $30 \mathrm{Mg}$, Ceftazidime $30 \mathrm{Mg}$, Aztreonam $30 \mathrm{Mg}$, Piperacillin $100 \mathrm{Mg}$, Imipenem $10 \mathrm{Mg}$, Ciprofloxacin $5 \mathrm{Mg}$, Ampicillin10 Mg, Ceftriaxone $30 \mathrm{Mg}$, Piperacillin + Tazobactam $30 \mathrm{Mg}$, Cefepime $30 \mathrm{Mg}$, Augmentin $30 \mathrm{Mg}$, Gentamicin $30 \mathrm{Mg}$, Cefoxitin 10Mg, Cephalothin $20 \mathrm{Mg}$, Cotrimoxazole $30 \mathrm{Mg}$, Cefotaxime $30 \mathrm{Mg}$, Colistin $10 \mathrm{Mg}$, Meropenem $30 \mathrm{Mg}$, Vancomycin $10 \mathrm{Mg}$, Teicoplanin $10 \mathrm{Mg}$, Erythromycin $30 \mathrm{Mg}$, Clindamycin $10 \mathrm{Mg}$, Oxacillin $10 \mathrm{Mg}$, Penicillin $30 \mathrm{Mg}$.

\section{MIC determination for the isolates}

MicroScan ${ }^{\circledR} \quad$ Automated Microbiology System, type TN dried panel, Pos ID 2
(Siemens, Tarrytown, NY) was used for detecting the Minimal Inhibitory Concentration (MIC). The interpretation standards for MICs of Clinical and Laboratory Standards Institute (CLSI, 2013) were used to determine antibiotic susceptibility of bacterial isolates. The antimicrobials tested for Gramnegative bacteria were Cefepime, Ceftazidime, Cefotaxime, Gentamicin, Imipenem, Meropenem, Amikacin, and Piperacillin $\backslash$ Tazobactam. The antimicrobials tested for Gram-positive bacteria were Teicoplanin, Clindamycin, Gentamicin, Augmentin, Oxacillin, Fox and Penicillin.

\section{RESULTS}

Purification of bacteria isolated from CF and non-CF patients was carried out using the streaking method where 49 pure isolates (25 isolates from $\mathrm{CF}$ and 24 isolates from non- $\mathrm{CF}$ patients) were obtained. Identification of the pure isolates from patients was carried out using cell and colony morphology, Gram staining and biochemical profiling. (Table1). Results indicated that the most predominant strain in CF patients was $P$. aeruginosa $(56 \%)$ followed by $S$. aureus and A. baumannii (16\%) and $K$. pneumoniae (12\%). Our data also indicated that the most common strains, identified in non-CF patients were $P$. aeruginosa and $A$. baumannii (37.5\%) followed by $S$. aureus (16.64\%) and $K$. pneumoniae $(8.32 \%)$

\section{Antibiotic Resistance Patterns Disk diffusion method:}

Table 2 shows the antibiotic susceptibility of isolated and identified bacterial isolates against all used antibiotics for Gram-negative bacteria; Pseudomonas aeruginosa, Acinetobacter baumannii, Klebsiella pneumonia and for Gram-positive S. aureus strain. Table 2 also revealed the number of Gram-negative CF Pseudomonas aeruginosa, Acinetobacter baumannii, and Klebsiella pneumonia samples in their ability to develop 


\title{
The Incidence of Some Most Common Bacterial Genus in Cystic Fibrosis Patients in Jeddah, Saudi Arabia
}

\author{
Ahmed M. Al-Hejin ${ }^{1,2^{*}}$ and Khadijah M. Bin Mahfouz ${ }^{1}$ \\ Department of Biological Sciences, Faculty of Science, P.O. Box 80203, \\ King Abdulaziz University, Jeddah, 21589, Saudi Arabia. \\ King Fahad Medical Research Center, P.O. Box 80216, \\ King Abdulaziz University, Jeddah, 21589, Saudi Arabia.
}

\begin{abstract}
Progressive loss of lung function due to the inflammatory response to bacterial colonization is the leading cause of mortality in cystic fibrosis (CF) patients. A greater understanding of these bacterial infections is needed to improve lung disease management. This research was aimed to isolate and identify biochemically the bacteria associated with CF patients. 25 bacterial isolates from CF patients were compared with 24 isolates from non-CF patients. Four different species were isolated in this study; $P$. aeruginosa, $S$. aureus, $K$. pneumoniae, and A. baumannii. In conclusion, these results showed that $\mathrm{CF}$ patients in Jeddah had uncommon species in CF patients.
\end{abstract}

Keyword: Incidence, Common, Bacterial Genus, Cystic Fibrosis, Patients

\section{INTRODUCTION}

$\mathrm{CF}$ is a common recessive genetic disease, which affects the entire body, causing progressive disability and often-early death [1]. Over 1,500 mutations have been identified [2]. The primary organ system involved in $\mathrm{CF}$ is the lungs [3]. There are no clinical trials of chronic non-antibiotic maintenance pulmonary therapies in infants and preschool-aged children with $\mathrm{CF}$, even though this is the population with the greatest potential for longterm benefit [4]. CF is most common in Ireland [5], Australia, New Zealand, the Middle East, Iran, Pakistan, India and Latin America. In Saudi Arabia, CF cases were reported to be 1 in 4243 children $[6,7]$. It affects persons without distinction of age or sex but can be asymptomatic in a great number of cases [8]. The ability of $P$. aeruginosa to persist and multiply in moist environments is of importance in cross-infection [9]. The aim of the present investigation was to determine the incidence of some most common bacterial genus in cystic fibrosis patients in Jeddah, Saudi Arabia.

MATERIALS AND METHODS

\section{Collection of patients' samples:}

The (CF) patients' samples were collected from King Faisal Specialist Hospital \& Research Center (Pediatric Clinic) and the (non-CF) Patients' samples were collected from King Faisal Specialist Hospital research 